TRANS · núm. I4 2 2010

DOSSIER $\cdot$ 53-60
El trabajo compara la forma anglosajona de enseñar a narrar un cuento y la manera en que los franceses enseñan a los estudiantes a hablar en público con fluidez para, así, plantear los problemas que existen en la enseñanza de la oratoria y la escritura en el contexto español. Se sugieren diferentes aproximaciones a la traducción (siguiendo a Walter Benjamin, Derrida, Ortega y Gasset) y se señalan algunos peligros, bondades y miserias de la traducción. Igualmente se incluyen comentarios sobre diferentes experiencias al traducir ficción norteamericana (T.C. Boyle, Patricia Highsmith, Richard Ford, Rick Moody, Cynthia Ozick) y francesa (Isabelle Eberhardt) y se analiza la experiencia de autotraducir mis propios cuentos al inglés con la ayuda de un escritor americano, descubriendo, asi, las razones y los significados inconscientes de cada una de las palabras.

PALABRAS CLAVE: traducción, escritura, ficción norteamericana, enseñanza, traducciones pedagógicas.

\title{
Traducir, Narrar, Traducirse
}

Isabel Núñez

Universidad Pompeu Fabra

\section{Translating, Storytelling and Translating Oneself}

This piece of work compares the Anglo-Saxon way to teach how to write a story with the French way to teach students how to speak fluently in public in order to approach Spanish problems in teaching to speak and write. It suggests some different approaches to translation (after Walter Benjamin, Derrida, Ortega y Gasset) and hints some dangers, blessings and miseries of translation. The article includes comments on different experiences translating American fiction (T.C. Boyle, Patricia Highsmith, Richard Ford, Rick Moody, Cynthia Ozick) and French fiction (Isabelle Eberhardt) and tells the experience of translating my own short stories to English with the help of an American writer, to discover the unconscious reasons and meaning of every word.

KEY WORDS: translation, writing, American fiction, teaching, educative traditions 
Siempre he admirado el hecho de que en el sistema educativo anglosajón, la asignatura que llaman English incluya enseñar a escribir a los 54 estudiantes contando una historia tal como la transmitirían oralmente a un oyente. Eso allana el camino a quienes deciden ser escritores, pero también a los traductores. Poder exponer algo o narrar por escrito de un modo sencillo, cercano al lenguaje oral, con ritmo preciso, es una gran ventaja. Después ya vendrán, si se desea, o si la historia, el contexto o nuestra naturaleza los requieren, los abarrocamientos y las complicaciones. Si quien escribe domina los rudimentos de esa narración casi oral, atraerá más fácilmente al lector para seguir una historia, sin perderse por el camino de la adjetivación excesiva, la digresión y los niveles erróneos de lenguaje.

El sistema educativo francés, además de promover decididamente la lectura, concede gran importancia a la exposición oral. El francés tiene una sintaxis más compleja y cartesiana y los estudiantes se acostumbran desde pequeños a exponer un tema semanalmente ante los demás. Esta simple práctica no sólo elimina el miedo a hablar en público, sino que acaba por dotar a cada estudiante de recursos y hábitos para formular sus ideas, argumentarlas, convencer, seguir un debate, etc. Y también ayuda a escribir.

Por desgracia, en nuestro país no se enseña ni una cosa ni otra. Muchas veces, para escribir y para traducir, tenemos que pasar años desaprendiendo lo que nos enseñaron. Algunos profesores de Traducción o de Humanidades pedimos a nuestros estudiantes universitarios que se limiten a utilizar el léxico que ya conocen o el nivel de lenguaje que pueden dominar, ya que la confusión de niveles, unida a la pretensión de utilizar recursos que no dominan o lenguajes impostados o alambicados, alternándolos con una sintaxis defectuosa o un léxico

pobre resultan mucho peores y nos recuerdan a la forma de expresarse de los agentes de policía, por ejemplo, que al abuso de tecnicismos recién adquiridos añaden la pobreza de elaboración y un conocimiento muy rudimentario de su lengua. Les ocurre a algunos traductores: su falta de dominio sintáctico y léxico en castellano no les ayuda a separarse de los modos propios del inglés o la sintaxis y los giros franceses. En traducción, se trata de que la lengua de destino fluya y de que el lector pueda no sólo comprender la historia que se le cuenta, sino abstraerse en ella, sin tener que recordar constantemente que se escribió en otra lengua. Y muchos estudiantes se gradúan convencidos de que, para escribir, hay que utilizar otro lenguaje distinto del que conocen. Este hecho, unido a la lectura insuficiente, empobrece la escritura y revierte en las dificultades de traducción. Sigue asombrándome que, entre los alumnos del posgrado de Traducción Literaria, muchos apenas hayan leído. ¿Cuál es entonces el objeto de esa especialización? ¿Cómo puede alguien creer que pueda traducir literatura sin haber leído?

Yo accedí a la traducción, como a casi todas las cosas importantes, por puro azar. Se trataba de un ejercicio afín para una lectora vocacional fascinada por las lenguas y que siempre quiso ser escritora. Descifrar jeroglíficos, traficar con palabras y silencios de una lengua (y una cultura) a otra constituía un reto que estaba en mi naturaleza abordar. Dice Ortega y Gasset (1940:444) que «cada lengua es una ecuación diferente entre manifestaciones y silencios. Cada pueblo calla unas cosas para poder decir otras. Porque todo sería indecible. De aquí la enorme dificultad de la traducción: en ella se trata de decir en un idioma precisamente lo que ese idioma tiende a silenciar».

Yo diría que los traductores buscamos en otras lenguas lo que nos falta en la nuestra. 
En esas lenguas otras encontramos la excusa, o digamos mejor el (aquí polisémico) pre-texto para forzar a nuestra lengua a decir lo que hasta ahora «no ha querido» decir. En este sentido, los traductores transformamos nuestra cultura, del mismo modo que el Quijote cambió para siempre el castellano y no sólo la lengua, sino la manera de ser en este país: nos hizo irónicos y burlones, de forma que del desengaño surge automáticamente el humor. Hace poco me contaron que en Madrid, a uno de esos corruptos que se había enriquecido sin límites y tenía la casa llena de obras de arte y otros tesoros, le llamaban «el aloe vera», y la razón era "porque tiene muchas propiedades ocultas». Ante el desastre que implica la corrupción política, el castellano, desengañado, apenas reacciona, pero hace un chiste. Esa tendencia a la mofa y la autoburla, parte del pesimismo español del que hablaba María Zambrano (v. 1987: 43), es una pequeña parte del legado cervantino. Nuestros estudiantes no lo saben y siguen sin leerlo, porque nadie les ha dicho que el Quijote es un libro divertidísimo, donde además Cervantes muestra su tristeza, su cansancio, su amargura, su pasión y su melancolía burlándose de sí mismo $\mathrm{y}$ de todos nosotros.

De los anglosajones, los traductores podemos tomar prestada la economía del lenguaje, envidiar su capacidad de formar nuevas palabras y forcejear para inventar las nuestras, arrancándonos a nuestra pereza y lentitud. También podemos cometer excesos. Hay un autor madrileño que escribe como si estuviera traduciendo literalmente letras de canciones: así inventó su estilo, tal vez para mostrarse como heredero de la cultura rock, conectar directamente con ese mundo sin pasar por la normativa del idioma, por su léxico natural. Hay también un traductor-escritor barcelonés que escribe como cuando traducía a los autores norteamericanos hijos de Gordon Lish o practicantes de la dangerous writing, escritura peligrosa que explora aquello que más asusta al escritor. Había que forzar la lengua para hacerla parecida a ese lenguaje, reinventado por algunos escritores norteamericanos como Tom Spanbauer o Chuck Palahniuk —recordemos al Palahniuk mecánico de camiones que escribía sus historias en un cuaderno, echado en el suelo bajo el camiónSon escritores de una cultura urbana violenta y desengañada y han querido crear como si nadie hubiera escrito antes que ellos, conectar con los que son como ellos, o sentirse expresados en su distancia. Un traductor no puede brillar con ese lenguaje, pero yo imagino que, identificado con aquello que ha logrado hacer decir a su propia lengua, no siempre quiere renunciar y opta por escribir en la misma lengua reinventada para traducirlos.

Según Walter Benjamin (1923/197I), la lengua más pura no es ningún idioma, sino que está en los intersticios entre todas las lenguas y sólo el traductor accede a esos intersticios. Ese traductor-escritor del que hablábamos se quedó atrapado en alguno de esos intersticios.

Pero de nuevo es Ortega (o. cit., p. I28) quien explica la dificultad de reunir dos condiciones necesarias para escribir (o traducir) bien (ibídem, p. I3I): «Escribir bien consiste en hacer continuamente pequeñas erosiones a la gramática, al uso establecido, a la norma vigente de la lengua... «Y el buen escritor es alguien que consigue que se le entienda al tiempo que renueva la lengua, dos cosas que parece imposible cohonestar».

Antes hablaba de tomar prestada la esencialidad del inglés, su encantamiento despojado y nature. Pero las generalizaciones plantean problemas. Veamos el caso de un autor al que he traducido extensivamente, T. C. Boyle, que al menos en gran parte de su obra recoge el legado 
dickensiano del lenguaje e intenta componer su escritura con un paisaje, unas aliteraciones y metáforas y una fonética y ritmo acordes con 56 la atmósfera interna que intenta componer, como Dickens (recordemos el principio de la dickensiana Casa desolada, donde el barro que todo lo enfanga y la niebla que todo lo vela metaforizan la corrupción y la falta de transparencia de la justicia, además de la melancolía y el sufrimiento de quienes dependen de ese expediente; hay tanto barro, dice Dickens, que es como si se hubieran retirado las aguas, los perros son indistinguibles del lodo, los caballos están cubiertos de él hasta las orejeras, el clima de noviembre es implacable, la gente entrechoca sus paraguas en una «infección generalizada de mal humor» e incluso los copos de nieve, oscurecidos por el hollín de las chimeneas, parecen guardar luto por la muerte del sol. Y los nombres de los abogados que recuerdan a palabras de lluvia o el apelativo del juez Milord (Mld) se convierte casi en mud, barro; y las palabras parecen imitar el ruido de las ruedas de un coche de caballos en el fangal) (vid. Nabokov, I980). ¿Por qué no recoger ese legado, cuando se trata de la misma lengua, y ésta es tan musical y con tantas palabras monosílabas o bisílabas como el inglés? T. C. Boyle escribía intentando ser siempre musical y rítmico, y además, con el diccionario al lado; el vocabulario -plantas, flores, fauna - era extenso y había que buscar. Una vez, cuando le conocí, le pregunté por una palabra - una herramienta - que nunca había encontrado. "No me extraña», me dijo, con su sonrisa maliciosa de viejo hippie. "No existe. La inventé. ¿Qué hiciste tú?». Le contesté que también la había inventado. "La próxima vez escríbeme», dijo, en una época en que no había correo electrónico ni fax, y me dio su dirección. Pero a pesar de las dificultades de léxico, yo sentía que avanzaba velozmente traduciéndole, y creo que era el ritmo, la fruición que me producía su manera de contar, su inspiración, que me resultaba contagiosa. Así fue en El fin del mundo, en Oriente, Oriente y en El balneario de Battle Creek. Por cierto que entonces no había Internet y para mí tuvo algo de reto feliz descubrir algo en el título y en la cita de entrada de East is East, que ahora nos solucionaría google en un momento. El título (literalmente: Oriente es Oriente) forma parte de una cita muy célebre de Rudyard Kipling ${ }^{I}$ que los niños anglosajones estudian en la escuela y que ha cobrado nueva vigencia con los conflictos de la globalización, las grandes migraciones y la dudosa teoría del «choque de civilizaciones». El editor barcelonés prefirió adoptar la opción del editor alemán y modificar el título por Oriente, Oriente, ya que los lectores castellanos no conocen el texto de Kipling. Y en cuanto a la cita que abría el libro, era de Uncle Remus, de Joel Chandler Harris, y yo, que había leído de pequeña una versión Disney de esas historias, no podía sospechar que me hallaba ante una de mis escenas favoritas. Y es que el autor hacía hablar a sus animales como los afroamericanos del sur, de modo que la Hermana Liebre decía «Bred and bawn in the briar patch, Br'er Fox, bred and bawn", queriendo decir «Bred and born» y donde Br'er era Brother. Llevaba el libro conmigo y al pasar por una librería inglesa le pregunté a la librera y me lo descifró. Entonces comprendí -y fue un hallazgo doblemente gozoso- que era el momento en que la liebre le suplica al zorro y a otros dos personajes que la han apresado que por favor, la desuellen viva, la sumerjan en un caldero hirviendo o la sometan a mil castigos igual de

I OH, East is East, and West is West, and never the twain shall meet / Till Earth and Sky stand presently at God's great Judgment Seat; B But there is neither East nor West, Border, nor Breed, nor Birth, / When two strong men stand face to face, tho' they come from the ends of the earth! 
terribles, pero sobre todo, que no la arrojen a los zarzales. Y cuando al fin la arrojan precisamente a esos zarzales, la liebre se burla de ellos saltando de zarza en zarza y canturreando que nació y se crió en el campo de brezo...

Ciertamente no podemos generalizar. Yo diría que cada escritor tiene su mundo propio, y decide -consciente o inconscientemente- qué parte del legado que otros escritores han hecho a su lengua y a la literatura recogerá o no. Y también dependerá de lo que sus necesidades internas y las de su historia le permitan recoger. Yo he traducido también a Patricia Highsmith, que es casi un extremo opuesto a T.C. Boyle. Nadie puede negarle a Highsmith sus magníficas ideas, la condición amoral de sus asesinos, esa encarnación de la banalidad del mal arendtiana, la demostración de que la violencia está en nuestro interior y el hecho de contenerla o dejarse llevar por ella dependa de factores internos que no suelen verse en el aspecto o la conducta cotidiana (por eso los vecinos de cualquier asesino insisten siempre en que parecía un ciudadano normal). Aunque era culta y en sus relatos juveniles y desechados incluía citas literarias, la Highsmith ha sido más bien descuidada con el lenguaje. En general, sus editores corregían sistemáticamente sus textos para la publicación, «la editaban», como suele decirse, pero llegó un momento en que se publicaban al mismo tiempo en inglés, alemán, francés y castellano, como ocurrió con Ripley Under Water (Ripley en peligro) y a los traductores nos tocaba hacer ese trabajo de corrección. Entonces la Highsmith aún vivía y yo recibí algún fax dirigido «a todos los traductores» con precisiones y cambios. En uno de ellos la autora explicaba algo del reflejo del agua en un cubo y en una piscina, con dibujos y flechas trazados por ella. Las precisiones me parecieron de una seriedad casi maníaca, aunque también tenía lógica que esos detalles fuesen para ella más importante que las palabras que utilizaba. Lástima que el papel de fax se borrase con el tiempo y que yo no tomara la precaución de fotocopiarlo para el recuerdo. Antes había traducido The Price of Salt (Carol), una novela de sus orígenes, publicada con pseudónimo en aquella época y tímidamente sáfica, donde la atmósfera de thriller highsmithiano quedaba flotando de fondo y yo estaba siempre esperando un asesinato... que nunca se producía. Años más tarde traduje sus cuentos póstumos (Una afición peligrosa y Pájaros a punto de volar), y los editores dieron la orden a todos los traductores de que corrigiéramos en lo posible. Se trataba de cuentos desechados, encontrados en cajones e inéditos o bien publicados en revistas en sus primeros años. Estaban llenos de errores, había incluso faltas - confundía todo el tiempo drought (sequía) con draught (corriente de aire, dosis...)-, había nombres cambiados, problemas sintácticos... Por eso me pareció injusto que alguien criticase mi traducción con dureza. Ciertamente yo cometí un error, un despiste imperdonable, que tampoco vieron los correctores de la editorial, escribí «tienda de informática» (aún no existía esa clase de tiendas) cuando se trataba de una ferretería (hardware store). No era importante la tienda en la historia, simplemente alguien pasaba junto a ella. Todos los traductores cometen algún error un día. Para juzgar una traducción, yo tengo en cuenta la fluidez y la libertad del castellano, la elegancia, el criterio, la búsqueda, un conjunto de cosas que ese reseñista no consideró, ni pudo leer el original inglés sin corregir para comparar. Se quejó de que pusiera «sordo como una tapia» en lugar de buscar una metáfora más audaz; pero si en inglés decía «stone deaf», ¿por qué iba a cambiar yo el registro de la autora buscando algo más ingenioso u original? El traductor puede corregir un texto defectuoso,

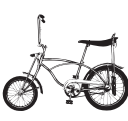

57 
pero no debe intentar mejorar la originalidad de un autor ni superar sus imágenes². Le molestó que, cuando la narradora se preguntaba si había 58 dejado encendido el fuego de los huevos que había puesto a cocer, al ir a comprobarlo viera que los huevos «estaban apagados». Era una forma coloquial, puesto que uno apaga el fuego y no los huevos, pero el castellano permite esas licencias en un contexto coloquial, como el que usaba la autora, que al entrar en un bar hacía a su protagonista pedir "M'N’ $X$ », y había que entender que se trataba de "ham on eggs», huevos con jamón. Para mí, la dificultad de traducir a Patricia Highsmith consistía en que su lenguaje no fluyera armoniosamente en inglés, que hubiera algo descuidado o incluso torpe en la expresión, exactamente al contrario de lo que me sucedía con T. C. Boyle. La facilidad para traducir a Patricia Highsmith o lo que me atrapaba al traducirla era más bien la excitación que provocan sus historias, la amoralidad de los personajes, el humor negro que subyace en su mirada sutil sobre el horror cotidiano.

También traduje la novela que lanzó a Richard Ford a la fama, The Sportswriter, El periodista deportivo. Una novela escrita en presente histórico, donde todo ocurre apenas en un día, y donde un escritor abandonado por la literatura, por su ex mujer y por su hijo, que murió, sobrevive dedicándose a escribir crónicas deportivas, como si esa alegre fugacidad de

2 En este terreno, hay disensiones: Rainer Maria Rilke fue muy criticado por su traducción «creativa» de la poeta francesa Louise Labbé, pues su versión alemana mejora y enriquece el original, tal como cuenta Alberto Manguel en su Historia de la lectura. Se discute si es legítimo que el escritor-traductor haga algo así, como el cuento que supuestamente añadió Galland a su versión de Las Mil y una Noches. Se puede perdonar - o no- al gran escritor que al traducir reescribe, sobre todo si el resultado es bueno, pero nadie defendería que haya que exigir al traductor esa traducción inventiva. las competiciones, donde todo parece volver a empezar cada vez y la suerte vuelve a repartirse sin memoria para todos, le consolara de su otra realidad, y al mismo tiempo, en su estilo tranquilo y levemente irónico se burla de la vida suburbana, de la familia americana de clase media y sus convenciones, y apunta a la tristeza y la desesperación que queda debajo, además de la melancolía de su propio duelo, que se filtra en sus recuerdos y pensamientos. El estilo era completamente distinto y entroncaba con la tradición norteamericana, Saul Bellow, Philip Roth, a veces Carver... Para mí, la traducción de ese libro quedó asociada también a un problema informático: eran los primeros tiempos de los procesadores de textos; el programa pirateado con el que trabajaba me borró la mitad del trabajo y el traductor que trabajaba conmigo creía que yo me había olvidado de guardarla... Así que hubo que repetirla y eso hizo que no aceptase otro libro de Ford, a pesar de que su historia me había acompañado y dejado huella (dos osos de peluche de mi hijo heredaron el nombre y apellido del narrador, Frank Bascombe). Más tarde fui seleccionada como traductora por el Time Magazine precisamente por esa traducción.

Traduje también a Rick Moody, otro de esos norteamericanos contemporáneos que escriben como si el mundo hubiera empezado con ellos, pero con personajes cargados de la melancolía energética de este mundo disparatado. Recuerdo que un loco de sus historias recitaba un fragmento bíblico antes de tirarse a la vía del tren, sin entrecomillado, pero reconocible pese a todo...

Otra experiencia especial fue traducir a Cynthia Ozick, aunque la intervención de un corrector (o correctora) que quería dejar su huella estropease mi satisfacción final al ver el libro impreso, demostrándome que era él (o 
ella) quien escogía las palabras. Ya en la primera página, donde yo ponía «que había llegado de Alemania» el corrector añadió "procedente de», donde yo ponía «Tenía sólo dieciocho años», el corrector puso "Tenía apenas dieciocho años», donde yo ponía «parco», él sustituía por «parsimonioso». Y así sucesivamente. ¿Cuál es la tarea del corrector? ¿Y hasta dónde llegan sus atribuciones? ¿Se trata de que imponga su gusto y su criterio también en los adjetivos y sustantivos, cuando es el traductor quien firma el trabajo? En otra ocasión, donde yo puse «Era una cuestión de orgullo» el corrector lo sustituyó por «Era una cuestión de puntillo». Cynthia Ozick es una gran novelista canadiense, con la solidez y el coraje de algunos narradores norteamericanos que incluso a una edad avanzada se atreven a abordar una novela ambiciosa y compleja. Ozick sí recogía a su manera — temáticamente, para darle una vuelta de tuerca, pero también en el estilo- el legado de la literatura victoriana, que es en cierto modo también madre de la literatura norteamericana y canadiense.

Ciertamente, en este país no se valora el trabajo del traductor, y la mezquindad de las tarifas es un síntoma, pero también lo es que cualquier corrector ávido de dejar su impronta o demasiado intervencionista pueda transformarlo todo, y que el editor no establezca mejor las funciones de cada uno. Una vez, en el catálogo de un museo de arte contemporáneo, la persona responsable de publicaciones cambió sin consultarme todas las citas que yo me había tomado el trabajo de buscar. Es decir, si el autor norteamericano citaba a Baudelaire en su traducción inglesa, yo no copiaba The Flowers of Evil, sino que aludía a la versión castellana de Las flores del mal, y si el autor citaba un ensayo de Walter Benjamin entonces inédito en castellano, yo citaba el título original alemán. Pues bien, alguien se ocupó de deshacer mi trabajo y ponerlo todo de nuevo en inglés; cuando lo vi, el libro estaba ya impreso. Otra vez, traduciendo un viaje de Colin Thubron por la ruta de la seda y las antiguas repúblicas soviéticas, como en la editorial no tenían un criterio definido, yo me ocupé de buscar uno, consultando a la RAE y al Diccionario del español urgente, y adapté todos los gentilicios... para luego descubrir que la editora me los había cambiado por la transcripción inglesa. En ese sentido, es una suerte convertirse en autora: ahí al menos los editores nos mandan las galeradas y el autor o la autora decide si acepta o no las correcciones.

Una experiencia gozosa fue la traducción de una selección de textos de Isabelle Eberhardt, incluida en la biografía que firmaba Eglal Errera y que publicó la editorial Circe. Si yo buscaba la verdad y la belleza en la escritura, aunque fuese a través de la escritura de otros, sus textos rebosaban de esas dos cualidades, y además, el encuentro con ese personaje libre y sin ataduras, que encontraba siempre la manera de vivir a su manera y ser ella misma sin limitaciones, en una época y una sociedad tan restrictivas, no sería casual. Años después leí sus obras completas, así como otras biografías suyas, y la incluí en mis conferencias y ensayos de escritoras olvidadas. A pesar de su rechazo de Occidente, la lengua francesa fluye y brilla con su poética y se enriquece de las palabras árabes que ella transcribe y siembra aquí y allá como pequeñas joyas que colorean sus relatos, y su mirada apasionada es capaz de realismo y humor al describir lo que la rodea, mientras con sus gestos traza involuntariamente el retrato del ser libre y excéntrico que fue, vestida de hombre y recorriendo el desierto con los nómadas, en una frugalidad que rozaba la miseria, recitando suras del Corán y convertida en morabito. Ahí era el personaje y su capacidad de encantamiento lo que sin duda arrastraba

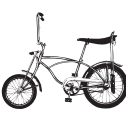

59 
mi prosa al traducirla, en un impulso de explicarla que no acabaría en la traducción, sino que seguiría en las conferencias. Isabelle Eberhardt 60 es un ejemplo de contradicciones y genialidad, y también un ejemplo de modernidad y de visión más allá de prejuicios y estereotipos, de conciliación con el mundo islámico, que ella sabe ver y explicar de otra manera. Para mí, la fruición de traducirla no ha terminado todavía y creo que la lengua multicolor de esta suiza arabizante y descendiente de rusos, que dibuja el desierto y las ciudades a sus puertas a principios del siglo $\mathrm{Xx}$, ha sido uno de mis encuentros más fructíferos con la lengua francesa.

Y por último, si al traducir narramos, la otra cara de ese esfuerzo sería traducir lo que narramos. Una artista neoyorkina quería leer mis cuentos y me pidió que le mandase uno para ponerlo en su software de traducción. El resultado que me mandó era surrealista, así que yo lo corregí y pasé a un inglés inteligible y se lo reenvié. Ella volvió a corregirlo. Yo objetaba a algunas correcciones, ella buscaba alternativas y de ese modo, yo, que escribo a ciegas, descubrí

que había una razón poderosa para elegir cada palabra de mis cuentos. Fue una experiencia enriquecedora para mí, y en cuanto a ella, que no se consideraba traductora de mis cuentos sino «finisher», empezó a escribir a partir de entonces y pronto abandonó la pintura por la literatura. $Y$ es que nadie es inmune al hecho de traducir ni a visitar esos intersticios que unen y separan nuestras lenguas.

RECIBIDO Y VERSIÓN FINAL: ENERO DE 2OIO ACEPTADO: FEBRERO DE $20 I O$

\section{REFERENCIAS BIBLIOGRÁFICAS}

Benjamin, Walter (197I) [I923]. «La tarea del traductor», en Angelus Novus. Barcelona: Edhasa, pp.

Nabokov, Vladimir (I980). Lectures on Literature, Nueva York: Harcourt

Ortega y Gasset, José (I940). «Miseria y esplendor de la traducción», en El libro de las misiones. Madrid: Espasa-Calpe, col. Austral, $\mathrm{n}^{\circ}$ Ioo

Zambrano, María (1987). Pensamiento y poesía en la vida española, Madrid: Endymión 